\title{
Ecosystem Controls on Methylmercury Production by Periphyton Biofilms in a \\ Contaminated Stream: Implications for Predictive Modeling
}

\author{
SCOTt C. BROOKS*1, Grace E. SCHWARTZ ${ }^{1}$, TOdD A.
} OLSEN $^{2}$, KATHERINE A. MULLER ${ }^{3}$

${ }^{1}$ Environmental Sciences Division, Oak Ridge National Laboratory, Oak Ridge, TN, 37831-6038, USA,

(*correspondence: brookssc@ornl.gov)

${ }^{2}$ Geosyntec Consultants, 3043 Goal Canal Drive, Suite 100, Rancho Cordova, CA, 95670, USA

${ }^{3}$ Earth Systems Science Division, Pacific Northwest National Laboratory, Richland, WA, USA

Periphyton biofilms in freshwater aquatic environments can be a net source of monomethylmercury (MMHg), as has been shown in East Fork Poplar Creek (EFPC) in eastern Tennessee, USA. Using enriched stable mercury $(\mathrm{Hg})$ isotopes, we quantified $\mathrm{Hg}$ methylation and $\mathrm{MMHg}$ demethylation in periphyton biofilms from EFPC across seasons, creek location, and under different light exposure. Methylation and demethylation rate potentials were estimated using a transient availability model ( $k_{m, t r a n s}$ and $k_{d, t r a n s}$, respectively) and compared to rate potentials estimated from a conventional full availability model $\left(k_{m, f u l l}, k_{d, f u l l}\right)$. The transient availability model accounts for competition for $\mathrm{Hg}$ and MMHg among sorption, desorption, oxidation, reduction, methylation and demethylation reactions. Rate potentials assuming transient availability averaged $15 \times$ and $9 \times$ times greater for $k_{m}$ and $k_{d}$, respectively, for the transient versus full availability models. Significant predictive relationships were obtained between environmental variables (season, location,

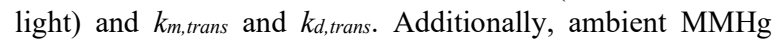
concentration in biofilms was significantly correlated with $k_{m, t r a n s .}$ Light exposure and season were significant predictors of $k_{m \text {,trans }}$ with greater values in full light exposure and in the summer. Season, light exposure, and location were significant predictors of $k_{d, t r a n s}$, which was highest in dark conditions, in the spring, and at the upstream location. In contrast, no significant predictive relationships were derived for $k_{m, \text { full }}$ or $k_{d, f u l l}$ and there was no relationship between ambient $\mathrm{MMHg}$ and $k_{m, f u l l .}$ These results underscore the importance of applying transient availability kinetic models to $\mathrm{MMHg}$ production data when estimating MMHg production potential and flux. 